\title{
Coordination as a Direct Process
}

\author{
Augusta Mela \\ LIPN-CNRS URA 1507 \\ Université de Paris XIII \\ 93430 Villetaneuse FRANCE \\ amQura1507.univ-paris13.fr
}

\author{
Christophe Fouqueré \\ LIPN-CNRS URA 1507 \\ Université de Paris XIII \\ 93430 Villetaneuse FRANCE \\ cf@ura1507.univ-paris13.fr
}

\begin{abstract}
We propose a treatment of coordination based on the concepts of functor, argument and subcategorization. Its formalization comprises two parts which are conceptually independent. On one hand, we have extended the feature structure unification to disjunctive and set values in order to check the compatibility and the satisfiability of subcategorization requirements by structured complements. On the other hand, we have considered the conjunction et (and) as the head of the coordinate structure, so that coordinate structures stem simply from the subcategorization specifications of $e t$ and the general schemata of a head saturation. Both parts have been encoded within HPSG using the same resource that is the subcategorization and its principle which we have just extended.
\end{abstract}

\section{Introduction}

Coordination has always been a centre of academic interest, be it in linguistic theory or in computational linguistics. The problem is that the assumption according to only the constituents of the same category (1) may be conjoined is false; indeed, coordinations of different categories (2)-(3) and of more than one constituent (4)-(5) should not be dismissed though being marginal in written texts and must be accounted for ${ }^{1}$.

\footnotetext{
${ }^{1}$ This research has been done for the French coordination et (and).
}

(1) Jean danse la valse et le tango (Jean dances the waltz and the tango.)

(2) Je sais son âge et qu'elle est venue ici. (I know her age and that she came here.)

(3) Un livre intéressant et que j'aurai du plaisir à lire.

(An interesting book and which I will enjoy to read.)

(4) Je demande ̀̀ Pierre son vélo et à Marie sa canne à pêche.

(I ask Peter for his bike and Mary for her fishing rod.)

(5) Pierre vend un vélo et donne une canne à pêche à Marie.

(Peter sells a bike and gives a fishing rod to Mary.)

We claim here that the "local combinatory potential" of lexical heads, encoded in the subcategorization feature, explains the previous linguistic facts: conjuncts may be of different categories as well as of more than one constituent, they just have to satisfy the subcategorization constraints.

We focus here on the coordination of syntagmatic categories (as opposite of lexical categories). More precisely, we account for cases of non constituent coordination (4), of Right Node Raising (5) but not for cases of Gapping.

Our approach which is independent of any framework, is easily and precisely encoded in the formalism of Head Driven Phrase Structure Grammar (HPSG) (Pollard and Sag, 1994), which is based on the notion of head and makes available the feature sharing mechanism we need. The paper is organized as follows. Section 2 gives a brief description of basic data and discusses some constraints and available structures. Section 3 summarizes previous approaches and section 4 is devoted to our approach. The french coordination with et serves throughout the paper as an example. 


\section{A brief description of Basic Data and Constraints}

The classical typology of coordination, i.e. coordination of constituents (1) and of non-constituents, hides some regularity of the phenomenon as it focuses on concepts of constituent and syntactic category.

A coordination of constituents is interpreted as one phrase without any gap. The constituents may be of the same category (1) as well as of different categories (2)-(3). However, this last case is constrained as examplified hereafter ${ }^{2}$.

(2) Je sais son âge et qu'elle est venue ici. (I know her age and that she came here.)

(2a) Je sais son âge et son adresse. (I know her age and her address.)

(2b) Je sais qu'elle a 30 ans et qu'elle est venue ici. (I know that she is 30 and that she came here.)

(2c) *Je sais à Marie et qu'elle est venue ici. * (I know to Marie and that she came here.)

(2d) Je demande l'addition et que quelqu'un paie. (I ask for the bill and for someone to pay.)

(2e) *Je rends l'addition et que quelqu'un paie. *(I give back the bill and someone to pay.)

In these examples, the coordinate structure acts as the argument of the verb. This verb must subcategorize for each constituent of the coordination and this is not the case in example (2c)-(2e). Note that modelizing coordination of different categories as the unification (i.e. underspecification) of the different categories would lead to accept the six examples or wrongly reject (2d) according to the descriptions used $^{3}$.

Coordination of more than one constituent are often classified as Conjunction Reduction (4), Gapping (1a-1b) and Right Node Raising (5) (Hudson, 1976).

(1a) Jean danse la valse et Pierre, le tango. (Jean dances the waltz and Pierre the tango.)

(1b) Hier, Jean a dansé la valse et aujourd'hui, le tango.

(Yesterday, Jean danced the waltz and today, the tango.)

In the case of Gapping structures, the subject (1a) and/or an extracted element (1b) is present in the two sides. The only allowed coordinated structure is [Jean danse la valse] et [Pierre le tango] for (1a) and [Hier, Jean a dansé la valse] et [aujourd'hui, le tango] for (1b) as wh-sentences on other parts ( $/ a$ valse] et [Pierre] or [la valse] et [Pierre le tango]) are impossible.

A contrario, in the case of Conjunction Reductions, wh-sentences as well as cliticization are al-

\footnotetext{
${ }^{2}$ The star ${ }^{*}$ marks ungrammatical sentences.

${ }^{3}$ Apart from ad hoc modelizations.
}

lowed referring to what follows the verb (as for coordination of constituents) and treating the arguments simultaneously on the two parts of the coordination:

(4a) Je sais à qui demander un vélo et une canne à pêche.

(I know who I ask for a bike and for a fishing rod.)

(4b) Je sais à qui les demander.

(I know who I ask for them.)

(4c) Je leur demande un vélo et une canne à pêche. ( $\mathrm{I}$ ask them for a bike and for a fishing rod.)

(4d) Je les leur demande. (I ask them for them.)

Let us remark that a comma is inserted between $\grave{a}$ Marie and sa canne à pêche in case of extraction before et as in (1b), indicating the two sentences have not necessarily to be analyzed in the same way:

(4e) Je demande à Pierre son vélo et à Marie sa canne à pêche.

(I ask Peter for his bike and Marie for her fishing rod.)

(4f) A Pierre, je demande son vélo et à Marie, sa canne à pêche.

(Peter, I ask for a bike and Marie, for a fishing rod.)

Two structures are available in case of Conjunction Reductions. One structure corresponds to a coordination of sentences with a gap of the verb after $e t$, the other one consists in taking the coordinate parallel sequence of constituents as only one structure. The previous facts argue for the second possibility (see also section 3 for criticism of deletion approach).

Last, note that gapping the verb is less compatible with head-driven mechanisms (and the comma in (4f) could be such a head mark, see (BEF, 1996) for an analysis of Gapping coordinations). It seems then that the structure needed for Conjunction Reduction is some generalization of the standard structure used for coordination of constituents. Our proposal is then focused on this extension. We do not care of Gapping cases as their linguistic properties seem to be different.

It remains to integrate Right-Node Raising and to extend these cases to more complicated ones. Section 4 includes examples of such cases and shows that our proposal can manage them adequately.

\section{Previous Approaches}

There exists a classical way to eschew the question "what can be coordinated ?" if one assumes a deletion analysis. Indeed, according to this approach (Chomsky, 1957; Banfield, 1981), only coordination of sentences are basic and other syntagmatic coordinations should be considered as coordinations of reduced sentences, the reduction being performed by deleting repeated elements. This approach comes up 
against insurmountable obstacles, chiefly with the problem of applying transformation in reverse, in the analysis process (Schachter, 1973).

A direct approach has been proposed at once by Sag \& al. (Sag et al., 1985) within the framework of Generalized Phrase Structure Grammar (GPSG), by (Pollard and Sag, 1994) within HPSG, and (Bresnan, 1986) within Lexical Functional Grammar (LFG). These approaches have tried to account for coordination of different categories in reducing the constraint from requiring the same category for conjuncts to a weaker constraint of category compatibility. Whatever the nature of subcategorization information may be, syntactical in GPSG, hybrid in HPSG, functional in LFG, two categories are compatible if they subsume a "common denominator", in this case a common partial structure.

Technically, the compatibility is checked by computing a "generalization" of categories and imposing the generalization comprises all features expected in the given context. For example, the context in (6), that is, the verb être (to be), expects a predicative argument and both categories NP and AP are just predicative categories.

(6) Il est le père de Marie et fier de l'être. (He is Mary's father and proud of it.)

However, this solution cannot be applied generally because all coordinations have not such "natural" intersection (see (2)). So we claim that we have nothing else to do but explicitly enumerate, within the head subcategorization feature, all the structures allowed as complement.

\section{Our Approach}

Our proposition involves three stages. We begin by formulating constraints on coordinate structures, then we define how to build the coordinate structures and we end by specifying how the previous constraints filter through such coordinate structures.

\subsection{Constraints on coordinate structures}

In order to precisely formulate the constraints on coordinate structures, we distinguish the role of functor and that of argument, where functor categories are those that bear unsatisfied subcategorization requirements, as it is the case in Categorial Grammars (Dowty, 1988). Lexical heads (1) are functors in relation to the arguments they select and, by composition, any expression that contains an unsaturated functor is a functor (5)-(7).

(7) Il prétend détester et refuse ces beaux spots lumineux.

(He claims to hate and refuses these beautiful spotlights.)

Arguments are the complements selected by the head ${ }^{4}$. An argument may often be realized by different categories. For example, the argument required by savoir (to know) may be a NP or a Completive: we say that the requirement is disjunctive and we represent the different alternatives within subcategorization feature disjunctive values. An argument specification is then a disjunction of categories. When the lexical head requires several complements (to ask somebody something), the requirement is said multiple or n-requirement. To the extent that disjunction only appears in argument specifications, a n-requirement is a multi-set of simple requirements. The choice of set (or more precisely multiset) rather than list value for the feature SUBCAT allows us to account for Je demande à Pierre son vélo as well as Je demande son vélo à Pierre. Gunji (Gunji, 1987) makes the same choice. However our criterion can be formalized in a theory whose order of arguments obeys to an obliqueness hierarchy.

Requirement inheritance. A functor may compose with another functor or with arguments. In functor-arguments composition, the resulting expression inherits the unsatisfied requirement from the functor when it is not empty. For example, in (5), both conjuncts inherit the unsatisfied requirement from their heads. Likewise the functor composition inherits a requirement from the unsatisfied functor ${ }^{5}$. In (7), prétend détester inherits the unsatisfied requirement of détester, i.e. the requirement of an object.

Adjuncts. To account for the continuum which exists from strictly subcategorized complements to adjuncts, we adopt the hypothesis suggested by (Miller, 1991) according to which adjuncts could be accorded the same status as arguments by integrating them into the subcategorization requirement through an optional lexical rule. That would enable us to account for coordination of adjuncts of different categories (3) as well as coordination of more than one constituent with adjuncts (10)-(11) below. Note that we may still have a special feature ADJUNCT in order to distinguish adjuncts from other complements if necessary. Note also that these lexical rules can be interpreted statically as well as dynamically. In the first case, the extended lexicon is pre-computed and requires no runtime application.

\footnotetext{
${ }^{4}$ In this paper, we restrict arguments to complements. In our HPSG encoding, they are treated in the SUBCAT feature. In a Borsley-like manner, we suppose a special feature for the subject. However, our approach can be generalized to subjects.

${ }^{5}$ In functor composition, functors cannot be both unsaturated: * Il promet de manger à sa mère des bananes. (* he promises to eat his mother bananas.), cf. the Incomplete Constituent Constraint (Pollard and Sag, 1994).
} 
Satisfiability conditions of requirements. We observe here that a coordination of different categories may appear as head complement when the head requirement is disjunctive and a coordination of more than one constituent appears when such a requirement is multiple. Last, functors may conjoin when their subcategorization requirements are compatible. These observations are synthesized in one coordination criterion.

The first observation is summarized in (C1) and illustrated in (2').

(C1) A subcategorization 1-requirement is satisfied either by one of the disjuncts or by a coordination of disjuncts.

(2') Je sais son âge /qu'elle est venue ici / son âge et qu'elle est venue ici.

(I know her age / that she came here / her age and that she came here.)

The second one is illustrated below, where subcategorization n-requirements are satisfied either by:

- a series of $n$ complements which satisfy respectively the $n$ requirements

(8) Je demande à Pierre son vélo et sa canne à pêche.

(I ask Peter for his bike and for his fishing rod.)

- a coordination of a series of this kind

(9) Je demande à Pierre son vélo et $\underline{\text { à Marie }}$ d'où elle vient.

(I ask Peter for his bike and Mary where she comes from.)

- a coordination may concern sub-series of arguments

(10) Pierre a acheté un livre à Marie et un disque à Pierre pour $100 \mathrm{~F}$.

(Peter has bought a book for Mary and a CD for Peter for 20\$.)

- or sequences of more than one constituent with adjuncts (11)

(11) J'ai vu Pierre hier et Marie lundi.

(I have seen Peter yesterday and Mary monday.)

- or adjuncts of different categories (3).

(3) Un livre intéressant et que j'aurai du plaisir à lire.

(An interesting book and which I will enjoy to read.)

All these situations are summarized in (C2):

(C2) A subcategorization n-requirement is satisfied by $m$ arguments, $0<m \leq n$, either by a sequence of $m$ arguments such that each argument satisfies one and only one element of the requirement or by a coordination of such sequences. The result has a $n-m$ requirement.
Note that (C1) and (C2) should be computed simultaneously in order to account for structures as (9). The notion of partial saturation in (C2) allows us to account for coordination of sub-series of arguments as in (10).

Functors coordination and compatibility of requirements. Functors may be simple (1), composed (7), of different structures (12) or partially saturated (13)-(5).

(12) Je pense offrir et que je recevrai des cadeaux. (I think to offer and that I will receive gifts.)

(13) Je pense recevoir de Jean et offrir à Pierre du caviar de Russie.

(I expect to receive from John and offer to Peter Russian caviar.)

In all cases, when they are conjoined, they share their arguments: there must therefore exist at least one possibility of satisfying them simultaneously. In this case, the unification of their subcategorization requirements succeeds and they are said to be compatible and the two functors may be conjoined. This unification has to account for disjunctive values.

Coordination criterion : satisfying and imposing requirements. As an entity can be both functor and argument (12)-(13) our coordination criterion (necessary condition) is the following one: the conjuncts must satisfy the same simple or multiple subcategorization requirement and impose compatible subcategorization requirements.

\subsection{Computing the subcategorization requirements compatibility}

We have now to define an extension of the usual unification $U$ of structures in order to compute the subcategorization requirements compatibility. This extension is an internal operation over the subcategorization requirements which accounts for disjunctive and set values. $\mathcal{U}$ is the unification of argument specifications defined from $U, \mathcal{U}^{+}$is its extension to n-requirements.

- Unification of two argument specifications $\alpha$ and $\beta$.

Let us have $\alpha=\bigvee_{k=1 \ldots p} s_{k}, \beta=\bigvee_{l=1 \ldots q} t_{l}$, with categories $s_{k}, t_{l}$, then

$\alpha \mathcal{U} \beta=\bigvee_{k, l} s_{k} \cup t_{l}$ for $k, l$ s.t. $s_{k} \cup t_{l}$ exists undefined if $s_{k} \cup t_{l}$ does not exist, $\forall k, l$

- Unification of two n-requirements $\Phi$ and $\Psi . \Phi=\left\{\alpha_{i} / i \in[1, n]\right\}$ and $\Psi=\left\{\beta_{i} / i \in[1, n]\right\}$ be 2 n-requirements, where $\alpha_{i}$ and $\beta_{i}$ are argument specifications, the extended unification $\mathcal{U}^{+}$of $\Phi$ and $\Psi$ is defined if there exists a permutation $p$ on $[1, n]$ such that $\alpha_{i} \mathcal{U} \beta_{p[i]}$ exists $\forall i \in[1, n]$. In this case $\Phi \mathcal{U}^{+} \Psi=\left\{\alpha_{i} \mathcal{U} \beta_{p[i]} / i \in\right.$ $[1, n]\}$ else $\Phi \mathcal{U}^{+} \Psi$ is undefined. 
Two n-requirements are compatible iff their unification $\mathcal{U}^{+}$succeeds.

We consider that conjoined functors should have the same valence ${ }^{6}$. Note that the unification of two $\mathrm{n}$-requirements is ambiguous because we may have several permutations which lead to success.

\subsection{How coordinate structures are built}

Until now we have just defined constraints on the coordinate structures but we did not mention how these structures are built. We want that a coordinate structure inherits features from its conjuncts without necessarily failing in case of conflicting values. The generalization method (Sag et al., 1985) has this objective but overgenerates because the conflicting values are ignored. In contrast, the use of composite categories (Cooper, 1991) keeps conflicting values within the connective " $\wedge$ ". Intuitively, if son âge (her age) is a NP and qu'elle est venue ici (that she came here) is a Completive, son âge et qu'elle est venue ici (her age and that she came here) is a conjunctive composite category NP^Compl.

The structuring of categories : composite and tuple of categories. We propose to extend the operation $\wedge$ to complex categories and to use a new connective $\langle\ldots\rangle$ in order to define tuple of categories. With these two connectives, a total structuring of categories is possible and all the coordinate structures may have a status. For example, the underlined expression in (14) will be represented by the structured category: $\left\langle P P,\left[\begin{array}{c}N P \wedge C o m p l \\ \text { Subcat } P P\end{array}\right]\right\rangle$.

(14) Je recommande à Pierre la lecture et qu'il s'inspire de la Bible.

(I recommend to Peter the lecture and that he inspires himself of the Bible.)

The extension to complex categories is not uniform. Coordinate structure features are not necessarily composites or tuples of corresponding features from each conjunct. In fact, features which are allowed to have conflicting values will be compounded, whereas other features as SUBCAT must unify. This structuring is encoded later within the definition of the lexical entry of et.

Lexicalization of the coordination rule. We consider, as in (Paritong, 1992), the conjunction et as the head of the coordinate structure. Consequently, coordinate structures no longer have to be postulated in the grammar by a special rule of coordination: they stem simply from the general

\footnotetext{
${ }^{6}$ This condition will forbid the conjunction of e.g. verbs with SUBCAT lists of different lengths, but which would have a unification under the alternative interpretation, thus avoiding sentences like ${ }^{*} J o h n$ bought and gave the book to Mary, (Miller, 1991).
}

schemata of the head saturation and the subcategorization specifications of the conjunction. For sake of simplicity, only binary coordination is treated here. (Paritong, 1992) accounts for multiple coordination as a binary structure where the comma has a similar function as a lexical conjunction. With that one restriction, the HPSG-like lexical entry of et can be:

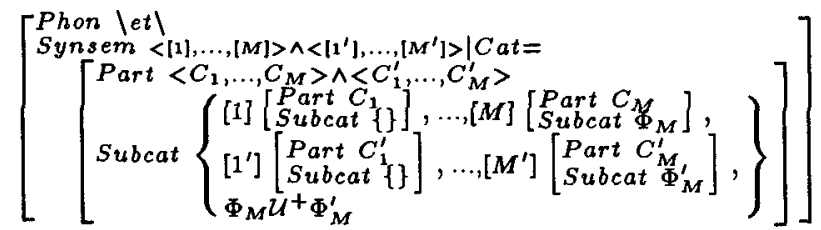

The following LP-constraint on the lexical entry of et ensures the correct order of conjunction and conjuncts:

$[i]<\operatorname{con} j<\left[i^{\prime}\right]$, where $i \in[1, M], i^{\prime} \in\left[1^{\prime}, M^{\prime}\right]$.

This LP-constraint is the minimum required to distinguish the two parts of the coordinate structure. However, the functor this coordinate structure (partially-)saturates may impose its own LPconstraint (e.g. an obliqueness hierarchy). In such a case, this LP-constraint has to be satisfied simultaneously by the two sets $\{[1], \ldots,[M]\}$ and $\left\{\left[1^{\prime}\right], \ldots,\left[M^{\prime}\right]\right\}$.

To represent the inheritance of the complements, here $\Phi_{M} \mathcal{U}^{+} \Phi_{M}^{\prime}$, we use a mechanism of argument composition inspired by (Hinrichs and Nakazawa, 1994): the conjunction et takes as complements the two conjuncts $\left\langle C_{1}, \ldots, C_{M}>\right.$ and $\left\langle C_{1}^{\prime}, \ldots, C_{M}^{\prime}\right\rangle$ which may remain unsaturated for their complements $\Phi_{M}$ and $\Phi_{M}^{\prime}$, and the set $\Phi_{M} \mathcal{U}^{+} \Phi_{M}^{\prime}$. The coordination of m-tuples, as well as the coordination of simple conjuncts $(M=1)$ stems from the saturation of the conjunction et. As noted in 4.1., only the last element of the tuple $C_{M}$ (or $C_{M}^{\prime}$ ) can be unsaturated and be the source of inheritance. Example of resulting HPSG-like analysis is given in figure 1 for the underlined phrase in (15).

(15) Jean conseille à son père d'acheter et à sa mère d'utiliser un lave-vaisselle.

(Jean advises his father to buy and his mother to use a dish washer.)

\subsection{How the constraints apply on coordinate structures}

We have now to define how arguments satisfy disjunctive and set requirements. Intuitively, if $\alpha_{i}$ is a (possibly disjunctive) argument specification, an argument (possibly composite) satisfies $\alpha_{i}$ iff each element of the composite category matches one disjunct of $\alpha_{i}$. Then, if $\Phi$ is a n-requirement, a tuple (or a coordination of tuples) of categories (possibly composite) satisfies $\Phi$ iff each element of the tuple (for each tuple) satisfies one and only one argument specification of $\Phi$. More formally: 


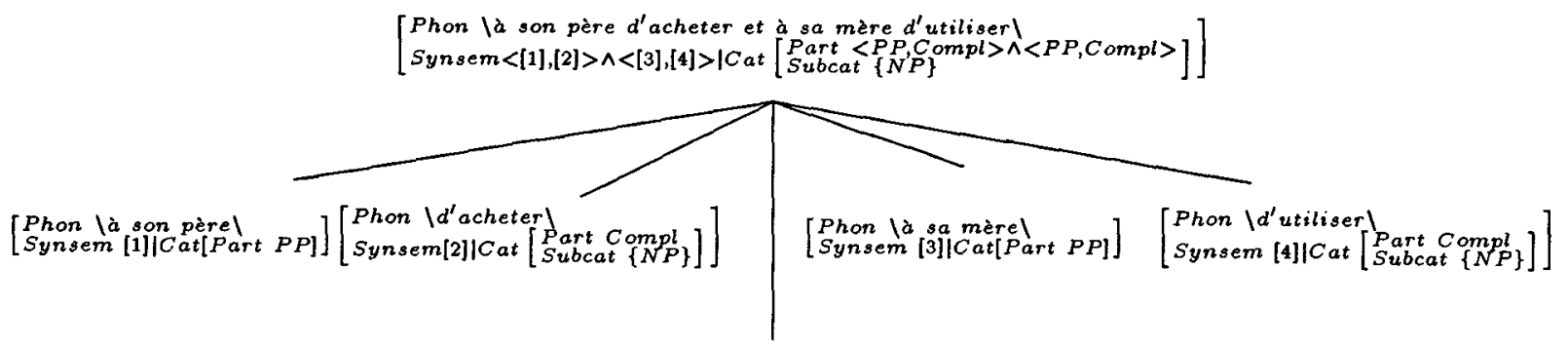

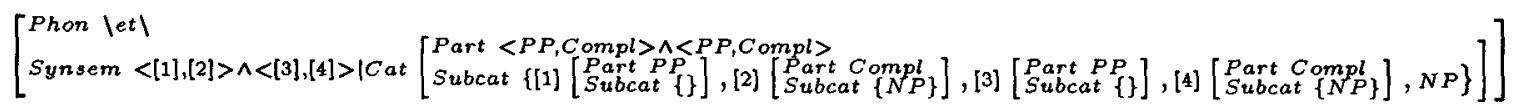

Figure 1: Analysis of à son père d'acheter et à sa mère d'utiliser

i) let $\alpha=S^{1} \vee \ldots \vee S^{p}$ be an argument specification, and $C=\bigwedge_{r=1 \ldots z} C_{r}$ be a composite category, then

$C$ satisfies $\alpha$ iff for each element of the composite category $C$, there exists one disjunct of $\alpha$ that matches it

(iff $\forall r \in[1, z], \exists l \in[1, p] / C_{r} \cup S^{l} \mathrm{ex}-$ ists).

ii) let $\Phi$ be a n-requirement s.t.:

$\Phi=\{\underbrace{S_{1}^{1} \vee \ldots \vee S_{1}^{p_{1}}}_{\alpha_{1}}, \ldots, \underbrace{S_{n}^{1} \vee \ldots \vee S_{n}^{p_{n}}}_{\alpha_{n}}\}$

and $\Sigma$ be a coordination of $p$ tuples (if $p>1$ ) or one tuple (if $p=1$ ) of composite categories $C_{i}^{k}$ s.t.:

$\Sigma=<C_{1}^{1}, \ldots, C_{n}^{1}>\wedge \ldots \wedge<C_{1}^{p}, \ldots, C_{n}^{p}>$

$C_{i}^{k}=\bigwedge_{r=1 \ldots z_{i}^{k}} C_{i, r}^{k}$

then

\begin{tabular}{|c|}
$\Sigma$ satisfies $\Phi$ iff each specification $\alpha_{i}$ has one and \\
only one realization in each tu- \\
ple of $\Sigma$ \\
(iff $\forall k \in[1, p], \exists$ a permutation $\pi_{k}$ \\
on $[1, n] / \forall i \in[1, n] C_{\pi_{k}[i]}^{k}$ satis- \\
fies $\left.\alpha_{i}\right)$.
\end{tabular}

Note that these requirement satisfiability conditions allows us to account for examples such as (9).

\subsection{A Coding in HPSG}

We extend here the functor saturation schemata to the coordination case, within the framework of Head Driven Phrase Structure Grammar (Pollard and Sag, 1994).

A subcategorization n-requirement is satisfied by $\mathbf{m}$ arguments, $m \leq n$, either by a sequence of $m$ arguments (m-tuple) or by a coordination of $m$ tuples. The result has a $n-m$ requirement.

\section{Saturation schemata ${ }^{7}$}

- partial $(\Psi \neq\{\})$ or total $(\Psi=\{\})$ of saturated complements $\left(\Psi^{\prime}=\{\}\right)$

- total $(\Psi=\{\})$ of complements, the last being partially $\left(\Psi^{\prime} \neq\{\}\right)$ or totally saturated $\left(\Psi^{\prime}=\right.$ \{\}$)$

$$
\begin{aligned}
& {\left[\text { Synsem } \mid \text { Cat }\left[\text { Subcat } \Psi \cup \Psi^{\prime}\right]\right.} \\
& \text { Branches = }
\end{aligned}
$$

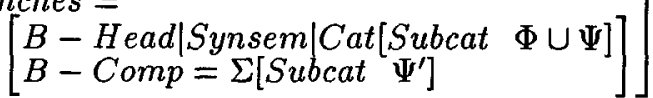

where $\Sigma$ satisfies $\Phi$ and:

- $\Phi=\left\{<S_{1}^{1} \vee \ldots \vee S_{1}^{p_{1}}>, \ldots,<S_{m}^{1} \vee \ldots \vee S_{m}^{p_{m}}>\right\}$ m-requirement, $\Psi n-m$ requirement

- $\Sigma=<C_{1}^{1}, \ldots, C_{m}^{1}>\wedge \ldots \wedge<C_{1}^{q}, \ldots, C_{m}^{q}>$ coordination of q m-tuples (if $q>1$ ) or one m- tuple (if $q=1$ ) of composite Synsem $C_{i}^{k}=$ $\bigwedge_{r=1 \ldots z_{i}^{k}} C_{i, r}^{k}$

- $\Psi$ or $\Psi^{\prime}$ must be empty

Example of resulting analysis is given in figure 2 for the underlined phrase in (15):

(15) Jean conseille à son père d'acheter et à sa mère d'utiliser un lave-vaisselle.

(Jean advises his father to buy and his mother to use a dish washer.)

Note that within a theory as HPSG which integrates syntactic and semantic information in a single representation, a whole range of lexically determined dependencies, e.g. case assignment, government (of particular prepositions) and role assignment, are modeled at the same time via subcategorization because the value of subcategorization feature is a complex of syntactic and semantic information.

\footnotetext{
${ }^{7} \Phi \cup \Psi$ is the set-union of $\Phi$ and $\Psi$
} 


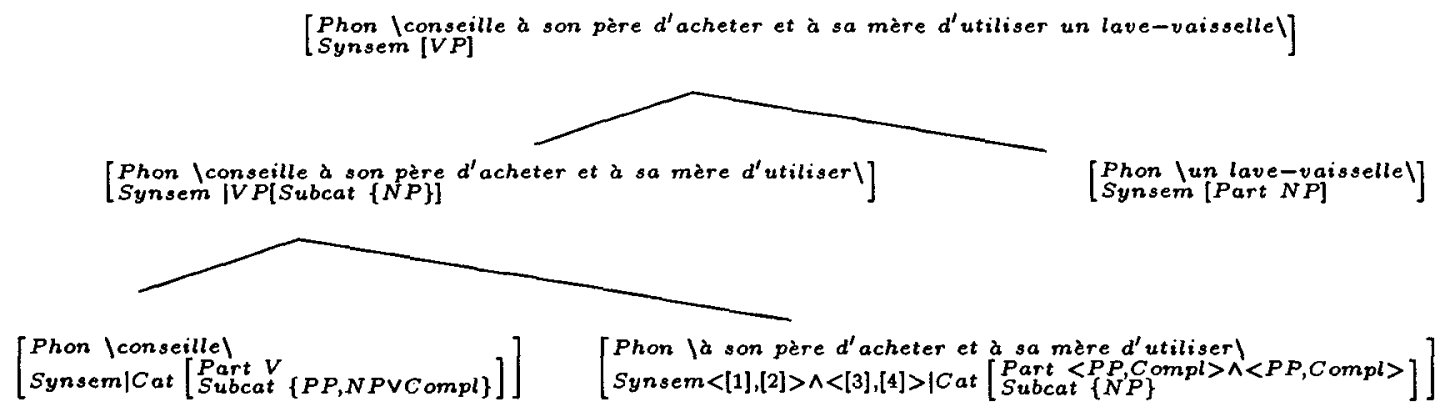

Figure 2: Analysis of conseille à son père d'acheter et à sa mère d'utiliser un lave-vaisselle

\section{Conclusion}

This approach based on concept of functor, argument and subcategorization allows us to account for many coordination data. Its formalization comprises two parts which are conceptually independent. On one hand, we have extended the feature structure unification to disjunctive and set values in order to check the compatibility and the satisfiability of subcategorization requirements by structured complements. On the other hand, we have considered the conjunction $e t$ as the head of the coordinate structure, so that coordinate structures stem simply from the subcategorization specifications of $e t$ and a general schemata of the head saturation. Both parts have been encoded within HPSG using the same resource that is the subcategorization and its principle which we have just extended.

It remains to know in which extent our approach can be used for other linguistic phenomena with symetrical sequences of more than one constituent (comparative constructions, alternative constructions):

(16) Paul donne autant de couteaux aux filles que de pièces aux garçons.

(Paul gives as much knives to the girls as coins to the boys.)

\section{References}

Banfield, A. 1981. Stylistic deletion in coordinate structures. Linguistics Analysis, 7(1):1-32.

Bouchard, L., Emirkanian, L., Fouqueré, C. 1996. La coordination à trouée : étude et analyse en GPSG et HPSG. In submission.

Bresnan, J., Kaplan, R., Peterson, P. 1986. Coordination and the Flow of Information Through Phrase Structure. Ms., CSLI, Stanford University.

Chomsky, N. 1957. Structures syntaxiques. Seuil.
Cooper, R. P. 1991. Coordination in unificationbased grammars. In Proceedings of the $A C L$, pages $167-172$.

Dowty, D. 1988. Type raising, functional composition, and non-constituent conjunction. In Categorial Grammars and Natural Language Structures. Richard T. Oehrle et al., pages 153-197.

Gunji, T. 1987. Japanese Phrase Structure Grammar. Dordrecht, Reidel.

Hinrichs, E. and T. Nakazawa. 1994. Linearizing AUXs in German Verbal Complexes. In German in Head-Driven Phrase Structure Grammar. J. Nerbonne, K. Netter and C. Pollard, pages 1137, CSLI Publications.

Hudson, R. 1976. Conjunction reduction, gapping and right-node raising. Language, 52(3):535-562.

Miller, P. 1991. Clitics and Constituents in Phrase Structure Grammar. Ph.D. thesis, Université libre de Bruxelles, Faculté de Philosophie et Lettres en Institut de Recherches en Intelligence Artificielle (IRIDIA).

Paritong, M. 1992. Constituent coordination in HPSG. In KONVENS 92, pages 228-237. Springer Verlag.

Pollard, C. and I. A. Sag. 1994. Head-Driven Phrase Structure Grammar. CSLI.

Sag, I., G. Gazdar, T. Wasow, and S. Weisler. 1985. Coordination and how to distinguish categories. Natural Language and Linguistic theory, (3):117171.

Schachter, P. 1973. Conjunction. In The Major structures of English. Holt, Rinehart and Winston, chapter 6.

Steedman, M. 1990. Gapping as constituent coordination. Linguistics and Philosophy, (13):207-263. 